\title{
Treatment-induced ABC-mediated multidrug resistance in PC-3 prostate cancer
}

\begin{abstract}
Background:The number of deaths from prostate cancer is still high due to ATP Binding Cassette (ABC)-Mediated Multidrug Resistance (MDR). Overexpression of $\mathrm{ABC}$ transporters causes multidrug resistance in most prostate cancer chemotherapies. $\mathrm{P}$-glycoprotein (P-gp) is one of the common drug transporters associated with MDR. There are no drugs approved by FDA to reverse MDR (inhibiting P-gp) in prostate cancer. This study utilized drug combination to reduce MDR expression by using 3-Bromopyruvate (3BPA) to potentiate the therapeutic effect of SC-514. SC-514 is a relatively new hydrophobic dug, which has been shown to have anti-cancer effects via inhibition of NF-KB-dependent gene expression in cancer cells. 3-BPA is an alkylating agent, glycolytic inhibitor, and an anticancer drug that has a great potential to enhance the effects of anticancer drugs.
\end{abstract}

Aim of study: This study aimed to reduce acquired and intrinsic ABC-mediated multidrug resistance (MDR) by increasing the drug efficiency of SC-514 via drug combination with 3-BPA.

Method: Cell titer glow assay, multidrug resistance efflux assay, immunofluorescence assay and ELISA assay were utilized to investigate the drug efficiency of SC-514 in combination with 3-BPA and the number of drug resistance GR-PC-3 cells and PC-3 cells after treatment.

Results:Combination of SC-514 and 3-BPA significantly decreased intracellular ATP and the number of MDR cells in GR-PC-3 and PC-3 prostate cancer cells. SC-514 and/3-BPA treatments reduce NF-KB activation, IL-6 expression, and BCL2 expression. However, SC514 and/3-BPA treatments increase the expression of Bax.

Conclusion: Combination of SC-514 and 3-BPA increased the therapeutic effect of SC-514 in prostate cancer treatment. The anticancer activities of SC-514 and 3-BPA in combination is promising for future drug development and drug combinations to completely reverse MDR in prostate cancer treatments.

Keywords: multidrug resistance, SC-514, drug combination, toxicity, potentiate, prostate cancer
Volume II Issue 5 - 2020

Toluleke Oloruntobi Famuyiwa,' James Kwasi Kumi Diaka,' Zoey Bowers,' Alyssa Leblanc, ' Waseem Asghar ${ }^{2}$

'Department of Biological Sciences, Florida Atlantic University, USA

${ }^{2}$ Department of Computer Engineering \& Electrical Engineering and Computer Science, Florida Atlantic University, USA

Correspondence: TolulekeOloruntobiFamuyiwa, Department of Biological Sciences, Florida Atlantic University, 3200 College Avenue, Davie, USA, Email tfamuyiva20I4@fau.edu

Received: September II, 2020 | Published: October 13, 2020

\section{Introduction}

\section{Increased incidence of prostate cancer}

Prostate cancer $(\mathrm{PCa})$ is the most common cancer in American men, after skin cancer. ${ }^{1}$ The American Cancer Society's estimates for prostate cancer in the United States for 2020 are: About 1 man in 9 will be diagnosed with prostate cancer during his lifetime. Prostate cancer is more likely to develop in older men and in African-American men. ${ }^{2-4}$

Cancer most primary prostate tumor cells are initially sensitive to androgen deprivation therapy (ADT). ${ }^{5}$ However, despite the advances in $\mathrm{PCa}$ treatment resulting in reduction in mortality rates, and increased patient survival, $\mathrm{PCa}$ still remains the most common non-cutaneous malignancy. ${ }^{6}$

Androgen deprivation treatment is very effective at inducing response for advanced or metastatic $\mathrm{PCa} .{ }^{7,8}$ However, more than half of those cases become resistant to androgen deprivation treatment after several years ${ }^{9}$ in what is termed castration resistant prostate cancer (CRPC) or hormone resistant (HR) prostate cancer. Hormone resistant (HR) prostate cancer cells had a higher expression of IL-6, compared to murine prostate cancer cell line (TRAMP-C1 cells). Even though $81 \%$ of prostate cancers are pathologically organ-confined at time of diagnosis. ${ }^{10} \mathrm{After}$ diagnosis prostate cancer can metastasized to other organs of the body if the treatment is not effective. 3-BPA is a known chemotherapeutic drug by itself. But is has limitations in treating prostate cancer. ${ }^{11}$ One of the ways to overcome limitations of 3-BPA is direct oxidation of NF- $\mathrm{kB}$ by Reactive Oxygen Species (ROS). The ROS produced inhibits DNA binding ability of NF-kB. ${ }^{12}$ This is very crucial to prevent survival of prostate cancer because NF-KB is one of the major pathways utilized by prostate cancer for survival. ${ }^{13}$ Cysteine, Cys-62 is in the Rel homology DNA-binding domain (RHD) and therefore its oxidation inhibits DNA binding. ${ }^{14}$ ROS production by anti-cancer drug can impact this oxidation. SC514 has been shown to be efficient in producing ROS. ${ }^{15,16}$ The ROS released by SC- 514 has the potential to enhance the therapeutic effect of 3-BPA and vice versa leading to a synergistic effect between 3-BPA and SC-514. ${ }^{16}$ However, there is no assurance that the synergistic effect between 3-BPA and SC-514 is strong enough to reduce MDR in prostate cancer as result of metabolic reprogramming of prostate cancer cells. ${ }^{17}$

Very few therapeutic approaches can disrupt metabolic reprogramming. This is because tumors usually consist of mixed populations of malignant cells, some of which seem to show drug-sensitivity, while others appear to be drug-resistant. ${ }^{18}$ Chemotherapeutic drugs may kill drug-sensitive cells but leave behind 
a higher proportion of drug-resistance cells. In previous studies, great efforts have been made to overcome MDR, but only a limited degree of success was achieved in clinical applications. ${ }^{19}$ Additionally, effective control of drug release rates canbe extremely important for clinical practice, because specific drug release rates should be formulated to overcome specific disease conditions.$^{20}$ Particularly, the development of MDR of prostate cancer cells is known to be a complex multistep process. MDR in cancer cells occur at different stages and different mechanisms requiring different treatment concentrations and different drug exposure time..$^{21}$ Therefore, in order to achieve an efficient drug delivery system for PCa therapies, the drug release profile in tumors should be maintained at optimum therapeutic concentrations with minimum fluctuation.

Furthermore, MDR has been demonstrated to have a unique broadspectrum resistance phenomenon. ${ }^{22-26}$ This broad-spectrum resistance was observed by overexpression of proteins such as the $\mathrm{ABC}$ transporters in tumor cells. $\mathrm{ABC}$ proteins antagonize drug activity. ${ }^{23}$ The $\mathrm{ABC}$ transporters including P-glycoprotein, are located in the cell membrane, and are highly dependent on ATP for activity. ${ }^{27,28}$ Inhibition of glycolysis and consequent inactivation of the $\mathrm{ABC}$ transporters promote intracellular retention of anti-cancer agents, thus highlighting their cytotoxic effects on malignant cells..$^{29,30}$

The mechanisms underlying MDR are rather complex. One of the mechanism, called transporter-mediated efflux is a major component that has received enormous attention. ${ }^{31,32}$ The transporter mediated efflux is controlled by efflux transporters. These efflux transporters, include $\mathrm{P}$-glycoprotein (ABCB-1/P-gp) ${ }^{33}$ and multidrug resistance proteins (MRPs). ${ }^{34} \mathrm{P}$-glycoprotein mediated efflux is one of the main mechanisms for multidrug resistance in $\mathrm{PCa}$ that can support prostateproliferation, angiogenesis and metastasis..$^{35-37}$

\section{Prostate cancer metastasis to the bone}

Patients with advanced stages of prostate cancer, can have conditions in which the cancer cells spread to the bones. This condition is known as bone metastases. Bone metastases is an extremely common event in patients with advanced prostate cancer, particularly those with castration-resistant prostate cancer (CRPC).$^{38}$ Bone metastasis commonly causes pain, increases the risk of fractures, and can lead to a life-threatening condition characterized by an increased amount of calcium in the blood called hypercalcemia. Treatments for bone complications may include drug therapy or radiation therapy. ${ }^{39,40}$ Despite the claim that $90 \%$ of adult cancer patients can be relieved of their pain, uncontrolled cancer-related bone pain is still a concern, particularly for patients living at home with metastatic bone disease. In fact, more than $90 \%$ of patients with metastatic prostate cancer have evidence of skeletal deformity and bone pain..$^{38}$ This lead to increased rates of bone fracture in metastatic prostate cancer patients. ${ }^{38}$ Research proceedings from the Oncology Nursing Society indicates that there is no effective drug to alleviate the pain from bone cancer metastasis. ${ }^{41}$ This bone cancer metastasis occurs when prostate cancer was treated the first time. However, the treatment was not effective therefore leading to prostate recurrence in a form that is more aggressive and dangerous.

\section{Energy pathways in prostate cancer cells(Figure I)}

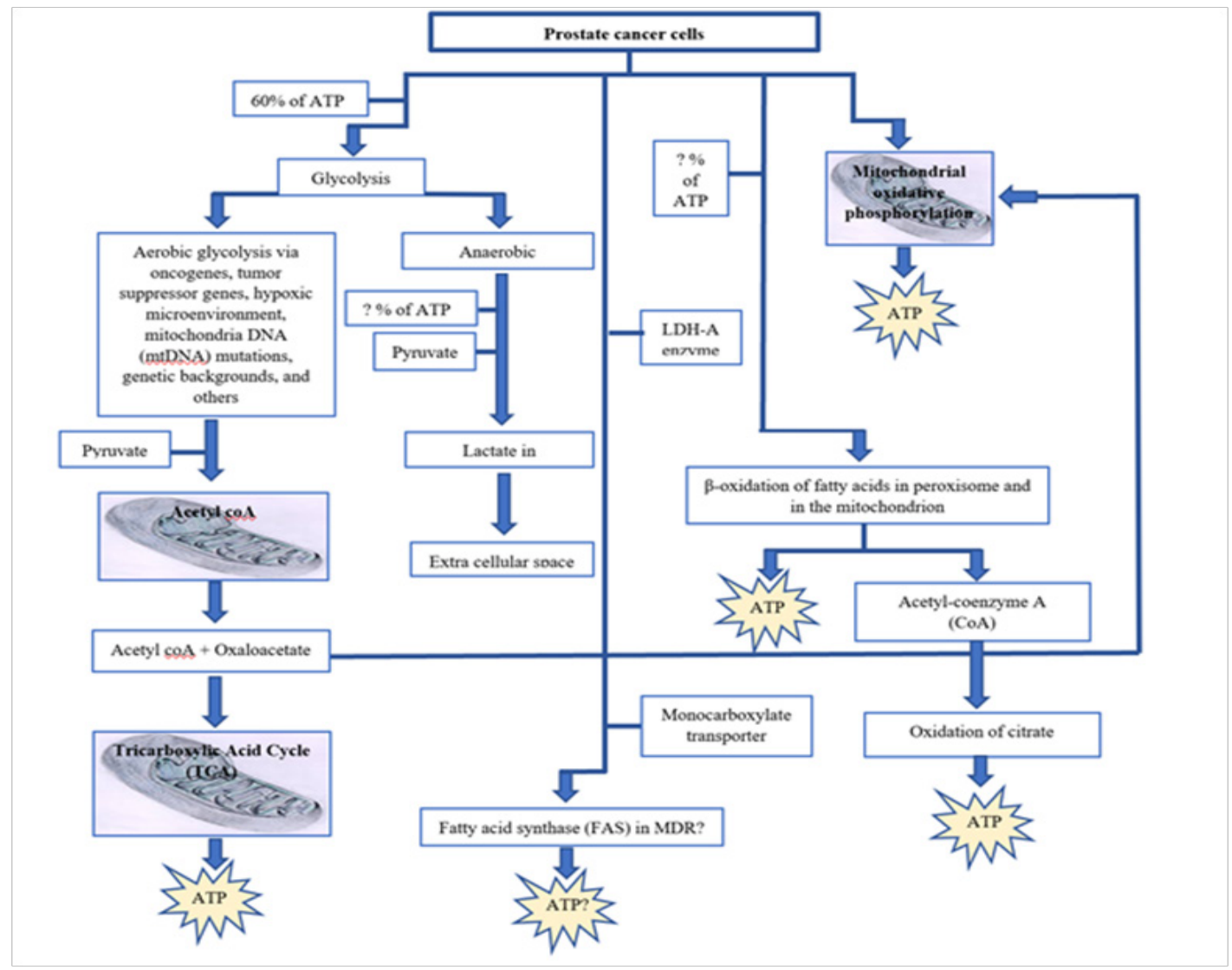

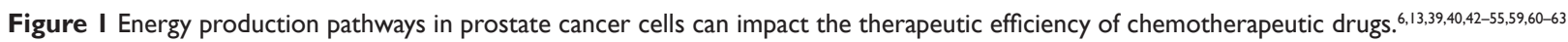




\section{Prostate cancer recurrence}

Prostate cancer recurrence may occur if ATP is made available to prostate cancer cells through any of the pathways indicated in fig 1 above. Like any other cancer, prostate cancer recurrence occurs when remission relapse. There are 3 types of recurrence (local, regional and distant). The type of recurrence depends on the location of the first tumor with respect to the final tumor location. ${ }^{56-58}$ The reasons and causes for the reoccurrence of prostate cancer is not fully elucidated. Some studies have observed a group of cancer cells. These cells are known as cancer stem cells or cancer initiating cells. ${ }^{59,60}$ Cancer stem cells are potential cause of recurrence of prostate cancer due to their tumor-forming capability, self-renewal, and resistance to chemotherapy and radiotherapy. ${ }^{61,62} \mathrm{This}$ recurrence may be linked to multidrug resistance in prostate cancer treatment.

Prostate cancer may relapse because of prostate cancer resistance to chemotherapeutic drugs. This condition is known as multidrug resistance (MDR). MDR has long been known as one of the challenges working against effective prostate cancer chemotherapy. ${ }^{63}$ In fact, the resistance to drugs by $\mathrm{PCa}$ cells is recognized as the primary cause of failure for chemotherapeutic treatments in prostate cancer. ${ }^{18,25,26}$ Growing evidence supports the idea that deregulated cellular metabolism is linked to such resistance. Indeed, both components of the glycolytic and mitochondrial pathways are involved in altered metabolism linked to chemo-resistance of prostate cancer. ${ }^{18}$ Multidrug resistance is characterized by resistance to a broad range of structurally and functionally unrelated chemotherapeutic drugs. ${ }^{64}$

In another situation, multidrug resistance (MDR) occurs after long-term chemotherapy, resulting in refractory cancer and tumor recurrence. Therefore, combatting MDR is an important step in prostate cancer treatment.

Several mechanisms of resistance have been identified including altered levels of multidrug resistance associated protein (an efflux pump), ${ }^{65,66}$ topoisomerase $\mathrm{II},{ }^{67}$ and glutathione $\mathrm{S}$ transferase. ${ }^{68}$ Overexpression of the MDR-1 gene product, P-glycoprotein (P-170), an integral plasma membrane protein involved in the active efflux of cytotoxic materials from the cell, is consistently associated with multidrug resistance in cultured cell lines selected for multidrug resistance and in certain tumors. ${ }^{69,70}$

P-170 is expressed in many normal tissues including kidney, adrenal glands, large intestine, and liver indicating that it is involved in normal physiological functions including detoxification and transport of lipophilic molecules. Tumors arising from tissues that normally express P-170 may be intrinsically resistant to chemotherapeutic agents or, alternatively, tumors that were initially responsive to chemotherapy may develop multidrug resistance during the treatment regimen and subsequently not respond to therapy. ${ }^{71}$

Multidrug resistance can be present at the time of diagnosis (intrinsic resistance) or can be acquired after initial treatment and remission of a cancer (acquired resistance). Although multiple mechanisms mediate multidrug resistance, the first mediator of multidrug resistance to be characterized at the molecular level was MDR1, also known as P-glycoprotein (Pgp) and ABCB1. ${ }^{63}$

The clinical importance of MDR1-mediated multidrug resistance has been best characterized in acute myelogenous leukemia. ${ }^{63}$ The role of MDR1 in solid tumors has been more difficult to discern, due to variations in methods of detection of MDR1 in tissues. Multiple efforts have been made to standardize methods for MDR1 detection using flow cytometry, immunohistochemistry and in situ hybridization. ${ }^{63,72}$ Most of these methods involve the use of monoclonal antibodies that are specific to MDR protein of interest. Several monoclonal antibodies have been produced to different epitopes of $\mathrm{P}-170^{73-77}$ and subsequently used in studies of various human tumor types. ${ }^{78}$

Multidrug-resistant cells contain a plasma membrane efflux pump, the multidrug transporter, which actively expels certain hydrophobic drugs from the cytosol to the cell exterior. These drugs are usually positively charged at physiological $\mathrm{pH}$. This efflux of positively charged molecules might deplete the cytosol of protons, raising the cytosolic $\mathrm{pH}$. The cytosolic $\mathrm{pH}$ of multidrug-resistant cells directly using a pH-sensitive dye coupled to a membraneimpermeable molecule was examined. ${ }^{79}$ Multidrug resistance is characterized by cross-resistance of human tumors to several different chemotherapeutic agents to which the patient has not been previously exposed. $^{79}$

A recent report detailing a series of multi-institutional trials to assess sources of variability in assays to detect P-170 in tumor specimens recommended standardization of approaches to the detection of P-170 in clinical specimens, including careful control of sample fixation and antigen preservation. ${ }^{80}$

The ABCB1 gene (previously MDR1), located at 7q21, encodes a membrane glycoprotein, which acts as an efflux pump and reduces intracellular drug concentrations. ${ }^{63,81-82}$ Gene copy number amplification is one of the chromosomal aberrations leading to the overexpression of the ABCB1 gene. It occurs intra-chromosomally, forming homogenously staining regions (HSR), or extrachromosomally, forming double minutes (DM). Both types have been reported in $\mathrm{ABCB} 1$ regional amplifications in acquired drug-resistant cell lines from various cancers. ${ }^{83}$

Although there are a considerable number of reports dealing with amplifications of the ABCB1 gene, little is known about the mechanisms underlying the amplification process. Our knowledge of the amplification process is very limited for amplification accompanied by other chromosomal rearrangements such as translocation, inversion, insertion, and deletion. One reason is complexity and heterogeneity of the rearrangements and another is lack of appropriate methods to monitor the specific chromosomal changes over time.${ }^{83} \mathrm{PCa}$ drug resistance may arise within PCa cells exploiting structures within the tumor micro-environment or stem cell niches to acquire invasive and survival advantages. ${ }^{6}$

\section{Intrinsic proliferation- and survival pathways -mediated drug resistance}

Drug resistance mechanisms study in $\mathrm{PCa}$, suggest that the alternatively-activated survival pathways may include activated receptor tyrosine kinases (RTKs). ${ }^{6}$ Moreover, epidermal growth factor (EGFR) and vascular endothelial growth factor receptor (VEGFR) are linked to signaling transduction pathways including Akt/PI3K or Ras/Raf/MEK/ERK pathways, which mediate cell proliferation and survival.

Treatment of prostate cancer with various agents targeting these and other pathways such as mammalian target of mTOR, ${ }^{84}$ MAPK/ ERK $^{85,86}$ VEGF, and its receptor VEGFR, have also been reported to be regulated by androgens in androgen-dependent tumors through activation of HIF $1 \alpha .^{87}$ Androgen depletion leads to direct 
up-regulation of VEGF-C, which in turns activates AR coactivator BAG-1L expression that enhances AR transactivation. ${ }^{88}$ Activation of other receptors and their pathways, such as interleukin 6 (IL-6) or $\mathrm{Wnt} / \beta$-catenin has also been reported to be involved in the crosstalk with AR. Similarly, Insulin-like growth factor 1 (IGF1) has also been reported to enhance AR function in low or absent androgen levels, and may promote the transition towards androgen-independence. ${ }^{89,90}$ Transforming growth factor $\beta$ (TGF $\beta$ ) was also reported to be overexpressed in $\mathrm{PCa}$, and shown to exert diverse functions in stromal tumor cells via SMAD-dependent or SMAD-independent signaling pathways. ${ }^{91}$ Nuclear factor-kappa B (NFkB)/IL-6. ${ }^{92}$ Hedgehog, ${ }^{93}$ EAR,,$^{94}$ and somatostatin receptor, ${ }^{95}$ have shown to either enhance or completely restore sensitivity to taxane-based therapy. These findings suggest that alternative signaling pathways may play a central role in drug resistance and provide valuable insight of overcoming the resistance by targeting these pathways.

However, once resistance to genistein is acquired, there are limited therapeutic options other than supportive care. ${ }^{96}$ Thus, it is critical to understand the mechanisms through which genistein-resistance develops in PCa. To mimic the clinical progression, we cultured and treat PC-3 cell lines with genistein, the cells that survived after $48 \mathrm{hrs}$ were labelled genistein-resistant prostate cancer cell lines.

\section{Results}

A good number of studies investigated the impact of genistein on prostate cancer (PCa) carcinogenesis. ${ }^{97-99}$ Our previous studies show that a subpopulation of prostate cancer cells survived after treating PC-3 prostate cancer cells with genistein in vitro $(98,99)$. This study stepped up the concentration of genistein in PC-3 prostate cancer treatment in vitro to $1000 \mu \mathrm{M}$ (Figure 2). However, we observed that a subdivision of the prostate cancer cells still survived at $1000 \mu \mathrm{M}$ gensitein treatment. This subdivision of prostate cancer cells is called genistein resistant prostate cancer cells (GR-PC-3). In this study, we determine the impact of SC-514 and 3-BPA on genistein resistant PC-3 prostate cancer cells (GR-PC-3) and PC-3 prostate cancer cell lines (PC-3).

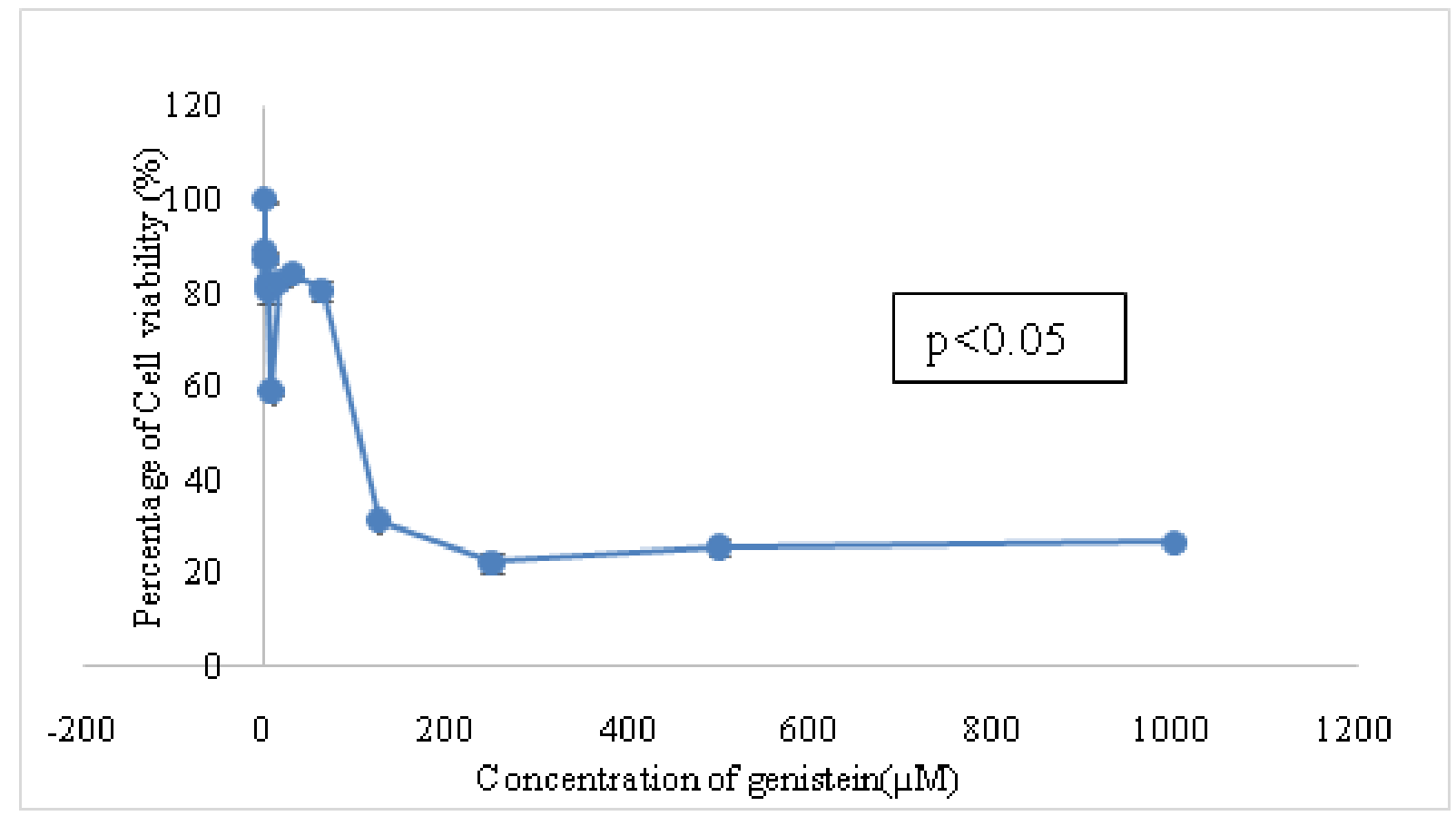

Figure 2 PC- 3 prostate cancer cells were treated with increasing concentration of genistein $(0.48 \mu M-1000 \mu M)$. Data represented are the mean of \pm SEM of three independent experiments. PC-3 prostate cancer cells that were viable after $48 \mathrm{hrs}$ of genistein treatment were labelledgenistein resistant PC-3 prostate cancer cells in this study. These cells were incubated at $5 \% \mathrm{CO}_{2}$ and $37^{\circ} \mathrm{Cfor}$ another $48 \mathrm{hrs}$. Cells were culture and treated (at their log phase, $48 \mathrm{hrs}$ culture and (80-90) \% confluence) with 3-BPA and/or SC-5I4 in 96 well plates.

\section{Percentage cell viability of PC-3 cells treated with genistein}

Before we investigated the number of MDR cells that survived after drug treatment, we utilized Cell titer glow assay to investigate the cell viability of the drug treated GR-PC-3 prostate cancer cells by quantifying amount of intracellular ATP in the cells (Figure 3). The result indicated that ATP level in form of luminiscence signal output decreases as drug concentrations increases. The combination treatment of 3-BPA and SC-514 consistently showed the lowest level of ATP or luminiscence signal output from $0.24 \mu \mathrm{M}-1000 \mu \mathrm{M}$ drug treatment.

\section{Cell titer glow cell viability assay measuring intracellular ATP in GR-PC-3}

Based on the cell viability of PC-3 prostate cancer cells mentioned previously, a population of prostate cancer cells survived after drug treatment with 3-BPA, SC-514, and 3-BPA + SC-514. Immunofluorescence assay was utilized to investigate the expression 
of p-glycoprotein in GR-PC-3 and PC-3 cells after drug treatment. The investigation was carried out by knowing the amount of drug that was retained in the cells and the number of drug resistant cells present after treatment(Table $1 \& 2$ ). The number of MDR cancer cells decreased for both the PC-3 cells (intrinsic resistant cells) and GR-PC-3 cells (acquired resistant cells from genistein treatment) as drug concentrations increased (Figure 4A \& 4B). However, GR-PC-3 indicated more sensitivity to drug treatment than PC-3. Hence, lower number of MDR PC-3 cells were observed in GR-PC-3 cells than PC-3 cells. Both GR-PC-3 and PC-3 cells indicated that combination treatment was the most effective in retaining drug inside the cells (Table $1 \& 2$ ) and reducing MDR cells (Figure 4A \& 4B).

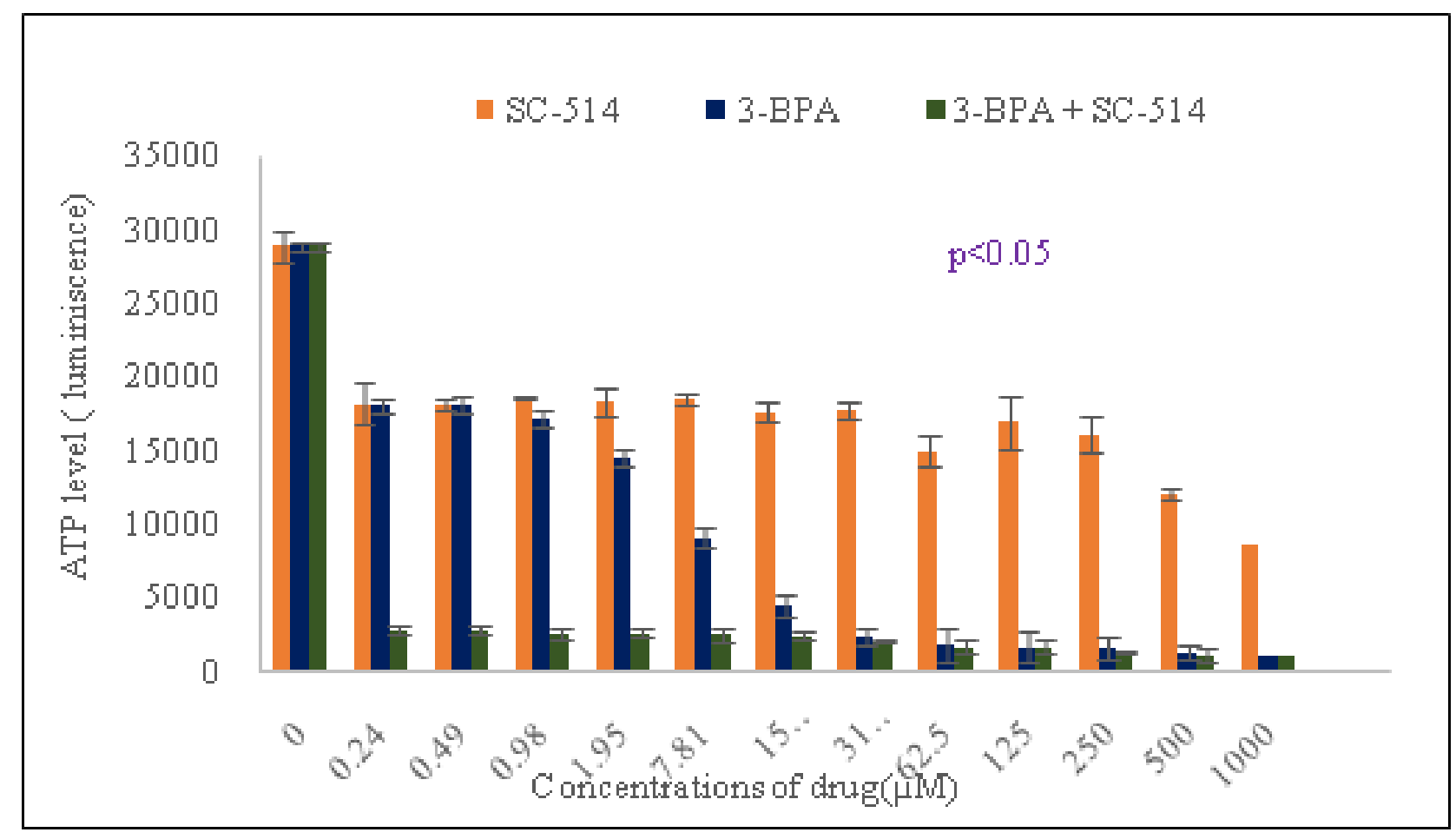

Figure 3 Intracellular ATP level correlates with luminescence signal output. A direct relationship exists between luminescence measured with the CellTiterGlo® Assay and the number of viable cells in cell culture. The number of viable cells is a measure of intracellular ATP in the cell culture. GR-PC-3 cells were cultured in a 96 -well plate in DMEM with I0\% FBS. GR-PC-3 cells were treated with 3-BPA, SC-5I4 and 3-BPA + SC-5I4.The values on the graph represent the mean \pm S.D. of three experiments in triplicates.

To further investigate MDR in GR-PC-3 prostate cancer cells, Confocal microscopy was utilized to view the morphology and fluorescence color of the drug treated GR-PC-3 cells indicating the nucleus of GR-PC-3 prostate cancer cells (5A), the position of the drug relative to the nucleus of prostate cancer cells (5B), MDR proteins expression levels via a glowing green color in GR-PC-3 prostate cancer cells (5C), an overlap between expression of drug resistance proteins and the position of the drug (5D), an overlap between the nucleus ofGR-PC-3 prostate cancer cells and cell tracker (5E), the control with the Cell Tracker $^{\mathrm{TM}}$ Red CMPTX dye, MDR protein (P-glycoprotein), and Hoechst 3342, but with no GR-PC-3 prostate cancer cells $(5 \mathrm{~F})$. The experimental design in figure $5 \mathrm{~F}$ confirmed that the color expression observed was from the interaction between the GR-PC-3 cells and the dye. Hoechst 3342 is not stained blue in figure $5 \mathrm{~F}$ because the nucleus of GR-PC-3 prostate cancer cells is not present. Hence, the fluorescence expression is majorly from the binding of the dyes to GR-PC-3 cells. The number of MDR GR-PC- 3 cells counted were very similar to the result from fluorescence microscopy.

\section{Immunofluorescence assay in genistein resistance PC-3 (GR-PC-3) cells}

Some of the drugs have been transported to the cell membrane and this also shows that the p-glycoprotein (a membrane protein) is concentrated more at the cell membrane. This is indicated by an overlap between expression of drug resistance proteins and the position of the drug (Figure 5).

We then utilized ELISA assay to investigate the expression of different pathways that controls carcinogenesis such as NF-KB pathway, IL-6 pathway, Bax pathway and BCL2 pathway. NF$\mathrm{KB}$ activation decreases as concentration of drug increases. There was a sharp decline in the level of NF-KB expression from control to $0.4 \mu \mathrm{M}$. However, the level of NF-KB expression from $0.4 \mu \mathrm{M}$ to $1000 \mu \mathrm{M}$ appear to be stable with the combination treatment of 3-BPA and SC-514 consistently impacting the lowest level of NF-KB expression (6A). IL-6 expression level decreases as concentration of drug increases. The expression level of IL-6 indicated resistance to treatment at the low concentrations (6B). Bax expression level 
increases as concentration of drug increases $(6 \mathrm{C})$. The combination treatment impacted the highest level of Bax at all drug concentrations.
BCL2 expression level decreases as concentration of drug increases (6D).

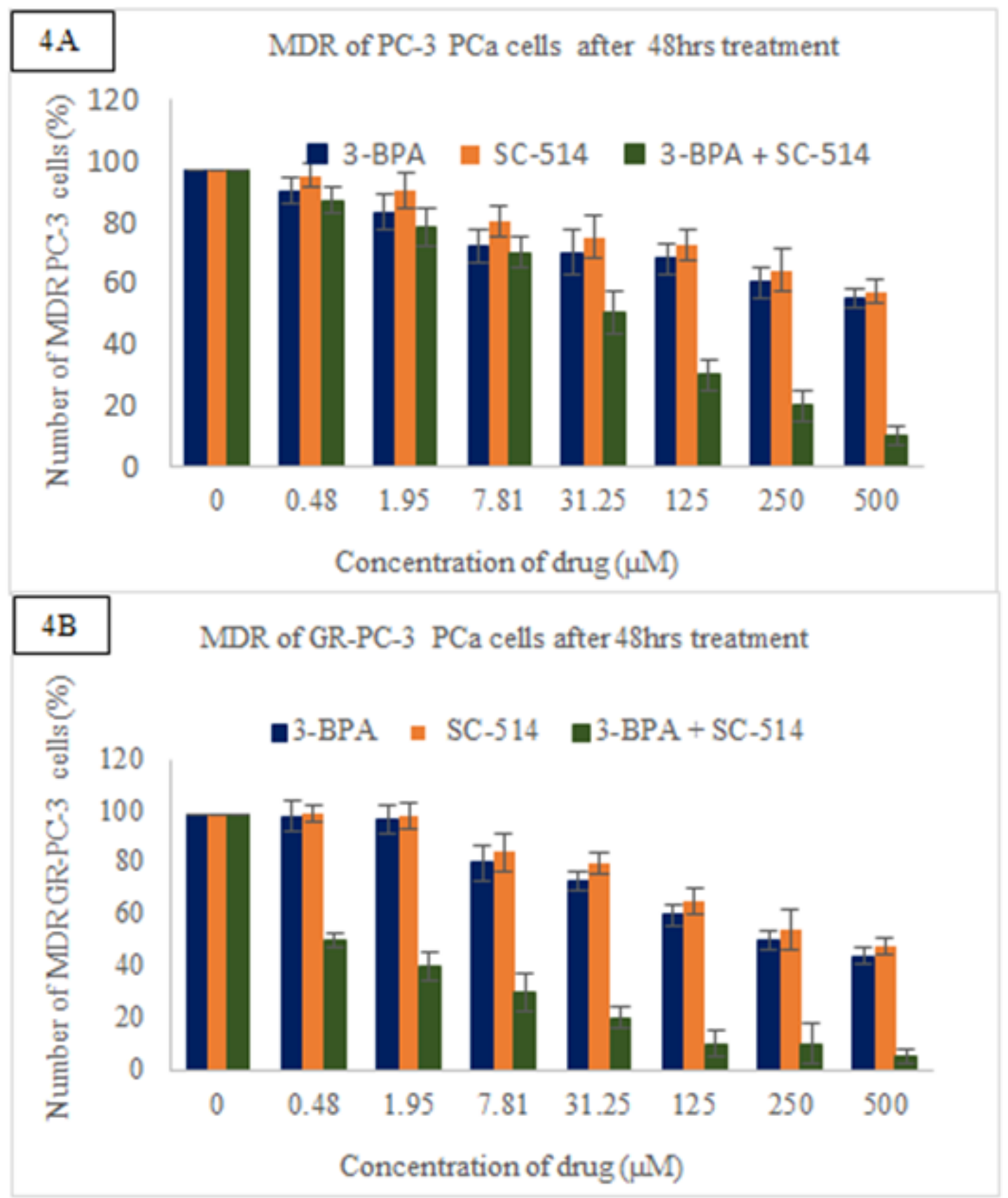

Figure 4A Shows immunofluorescence analysis results detecting P-glycoprotein-antibody interaction and cell tracker tagged to 3-BPA and/or SC-5I4. The green fluorescence from p-glycoprotein-antibody interaction estimated the number of MDR PC-3 PCa cells after treatment. This figure shows the number of MDR PC-3 cells observed after 48hrs treatment with 3-BPA, SC-514, and 3-BPA +SC-5I4. Data represented are the mean of \pm SEM of three independent experiments.

Figure 4B Shows immunofluorescence analysis results detecting P-glycoprotein-antibody interaction and cell tracker tagged to 3-BPA and/or SC-5I4.The green fluorescence from p-glycoprotein-antibody interaction estimated the number of MDR GR-PC-3 PCa cells after treatment. This figure shows the number of MDR GR- PC-3 cells observed after 48hrs treatment with 3-BPA, SC-5I4, and 3-BPA +SC-5I4. Data represented are the mean of \pm SEM of three independent experiments. 

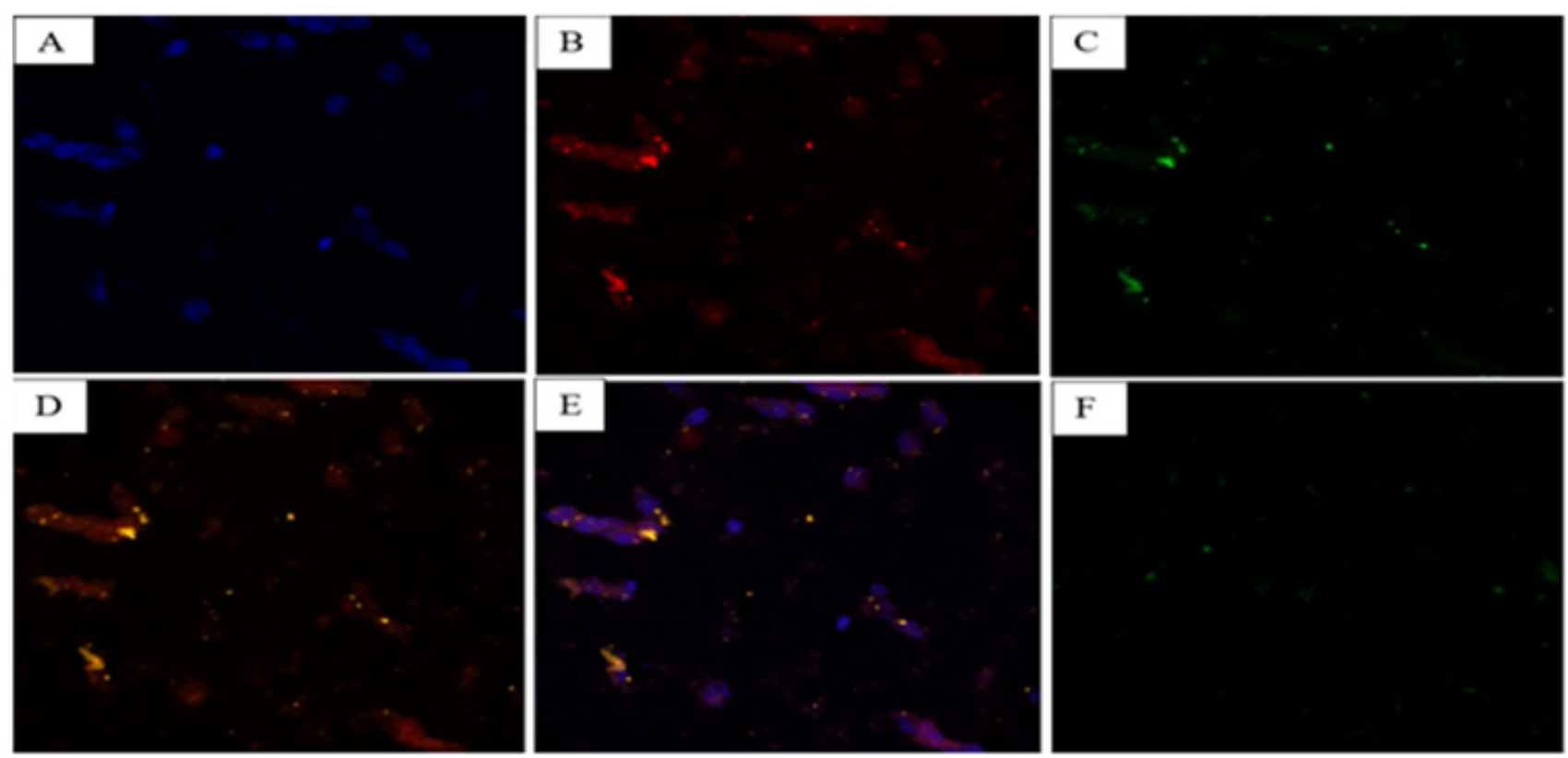

Figure 5 This figure shows the result of functionalizing SC-5 I 4 drug with fluorescent tag offering a useful visualization tool for tracing, localization, and clearance of the Cell Tracker ${ }^{\text {TM }}$ Red CMPTX dye relative to the nucleus of prostate cancer cells. The nucleus of the prostate cancer cells was stained with Hoechst 3342. P-glycoprotein expression in drug resistant, sensitive and viable GR-PC-3 prostate cancer cells were investigated via reactivity with p- 170 antibody by indirect immunofluorescence. The visualization and localization of MDR protein (P-glycoprotein) relative to the nucleus of the prostate cancer cells was observed. Figure $5 A$ shows the nucleus of GR-PC-3 prostate cancer cells stained blue by Hoechst 3342 . Figure $5 B$ shows the red color in GR-PC-3 prostate cancer cells indicating the position of the drug relative to the nucleus of prostate cancer cells. Figure $5 C$ shows MDR proteins expression levels via a glowing green color in GR-PC-3 prostate cancer cells. Figure 5D shows the overlap between MDR proteins and cell tracker (yellow color). Figure 5D shows an overlap between expression of drug resistance proteins and the position of the drug. Figure 5E shows purple color (nucleus of prostate cancer cells + cell tracker). Figure $5 \mathrm{~F}$ indicates the control with the Cell Tracker ${ }^{T M}$ Red CMPTX dye, MDR protein (P-glycoprotein), and Hoechst 3342. But with no GR-PC-3 prostate cancer cells.

Table I Shows immunofluorescence analysis results detecting p-glycoprotein-antibody interaction and cell tracker tagged to 3-BPA and/or SC-5 I4. The green fluorescence from p-glycoprotein-antibody interaction estimated the number of MDR PC-3 PCa cells after treatment. The red fluorescence from cell tracker tagged to 3-BPA and/or SC-5I4 indicated the quantity of drug inside the PC-3 PCa cells after 48hrs treatment with 3-BPA, SC-5I4, and 3-BPA + SC-5I4 treatment. We established a standard that specimen size (quantity of drug inside PC-3) greater than $3 \mathrm{~mm}$ length=abundant, specimen size (quantity of drug inside PC-3) between Imm-3mm length=traces, specimen size (quantity of drug inside PC-3) less than I $\mathrm{m}$ length= less than traces.

\begin{tabular}{|c|c|c|c|c|c|c|}
\hline $\begin{array}{l}\text { Concentration } \\
\text { of drug }(\mu \mathrm{M})\end{array}$ & $\begin{array}{l}\text { Quantity of } \\
\text { 3-BPA in cells }\end{array}$ & $\begin{array}{l}\text { Number of } \\
\text { MDR cells (\%) }\end{array}$ & $\begin{array}{l}\text { Quantity of in } \\
\text { cells SC-514 }\end{array}$ & $\begin{array}{l}\text { Number of } \\
\text { MDR cells (\%) }\end{array}$ & $\begin{array}{l}\text { Quantity of 3-BPA } \\
+ \text { SC-514 in cells }\end{array}$ & $\begin{array}{l}\text { Number of } \\
\text { MDR cells (\%) }\end{array}$ \\
\hline 0 (Control) & none & 97 & None & 97 & None & 97 \\
\hline 0.48 & $<$ traces & 90 & $<$ traces & 95 & $<$ traces & 87 \\
\hline 1.95 & $<$ traces & 83 & $<$ traces & 90 & $<$ traces & 78 \\
\hline 7.81 & traces & 72 & Traces & 80 & Traces & 70 \\
\hline 31.25 & traces & 70 & Traces & 75 & Traces & 50 \\
\hline 125 & traces & 68 & Traces & 72 & $>$ traces & 30 \\
\hline 250 & traces & 60 & Traces & 64 & $>$ traces & 20 \\
\hline 500 & $>$ traces & 55 & $>$ traces & 57 & $>$ traces & 10 \\
\hline
\end{tabular}


Table 2 Shows immunofluorescence analysis results detecting P-glycoprotein-antibody interaction and cell tracker tagged to 3-BPA and/or SC-5I4.The green fluorescence from p-glycoprotein-antibody interaction was utilized to estimate the number of MDR in genistein resistant PC-3 PCa cells (GR-PC-3) after treatment. The red fluorescence from cell tracker tagged to the drugs indicated the quantity of drug inside the genistein resistant PC-3 PCa cells (GR-PC-3) after $48 \mathrm{hrs}$ treatment with 3-BPA, SC-5I4, and 3-BPA + SC-5I4 treatment. We established a standard that specimen size (quantity of drug inside GR-PC-3) greater than $3 \mathrm{~mm}$ length = abundant, specimen size (quantity of drug inside GR-PC-3) between I mm - 3mm length=traces, specimen size (quantity of drug inside GR-PC-3) less than Im length= less than traces.

\begin{tabular}{|c|c|c|c|c|c|c|}
\hline $\begin{array}{l}\text { Concentration } \\
\text { of drug }(\mu \mathrm{M})\end{array}$ & $\begin{array}{l}\text { Quantity } \\
\text { of } 3 \text {-BPA in } \\
\text { cells }\end{array}$ & $\begin{array}{l}\text { Number of } \\
\text { MDR cells (\%) }\end{array}$ & $\begin{array}{l}\text { Quantity of SC- } \\
514 \text { in cells }\end{array}$ & $\begin{array}{l}\text { Number of } \\
\text { MDR cells (\%) }\end{array}$ & $\begin{array}{l}\text { Quantity of } 3-B P A+ \\
\text { SC-5 I } 4 \text { in cells }\end{array}$ & $\begin{array}{l}\text { Number of } \\
\text { MDR cells (\%) }\end{array}$ \\
\hline 0 (control) & none & 99 & None & 99 & None & 99 \\
\hline 0.48 & none & 98 & None & 99 & Traces & 50 \\
\hline 7.81 & traces & 80 & None & 84 & Traces & 30 \\
\hline 31.25 & traces & 73 & None & 80 & Traces & 20 \\
\hline 125 & traces & 60 & Traces & 65 & Traces & 10 \\
\hline 250 & traces & 50 & Traces & 54 & $>$ Traces & 10 \\
\hline 500 & $>$ traces & 44 & $>$ Traces & 48 & Abundant & 5 \\
\hline
\end{tabular}

\section{ELISA activation of in PC-3 prostate cancer cells (Figure 6)}

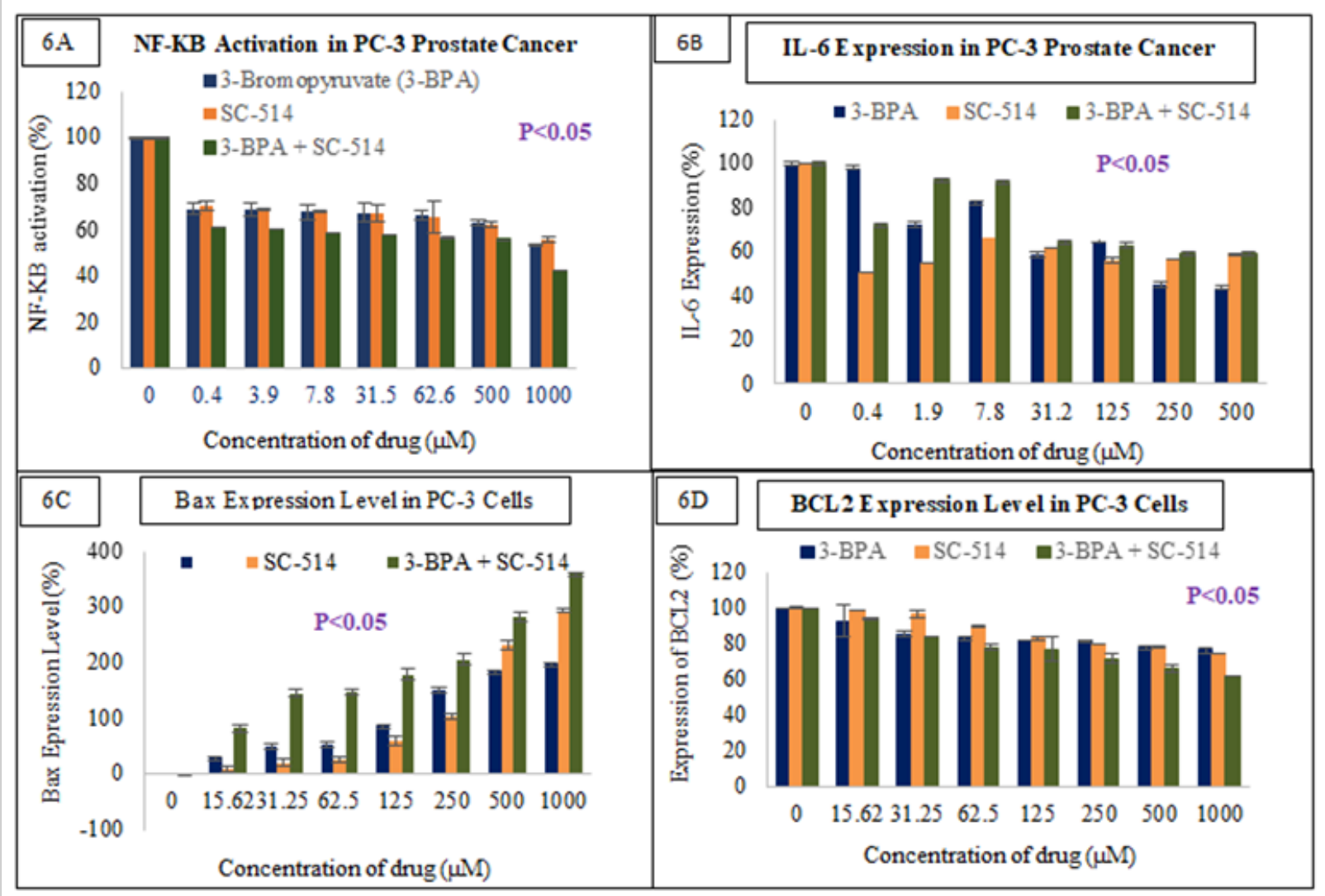

Figure 6 ELISA assay was utilized to investigate various pathways involved in prostate cancer carcinogenesis after treating PC-3 prostate cancer cells with SC-5I4 and/or 3-BPA. Fig 6A indicated that SC-5I4 and/3-BPA treatments reduce NF-KB activation. Fig 6B showed that SC-5I4 and/3-BPA treatments reduce IL-6 expression. Fig 6C indicated that SC-5I4 and/3-BPA treatments increase the expression of Bax. Figure 6D showed that SC-5I4 and/3-BPA treatments reduce $B C L 2$ expression. Data represented are the mean of \pm SEM of three independent experiments. This study showed how these different pathways influence apoptotic cell death. Apoptotic cell death is controlled by the interplay between multiple pathways such as IL-6, NF-KB, BL2 and Bax. 


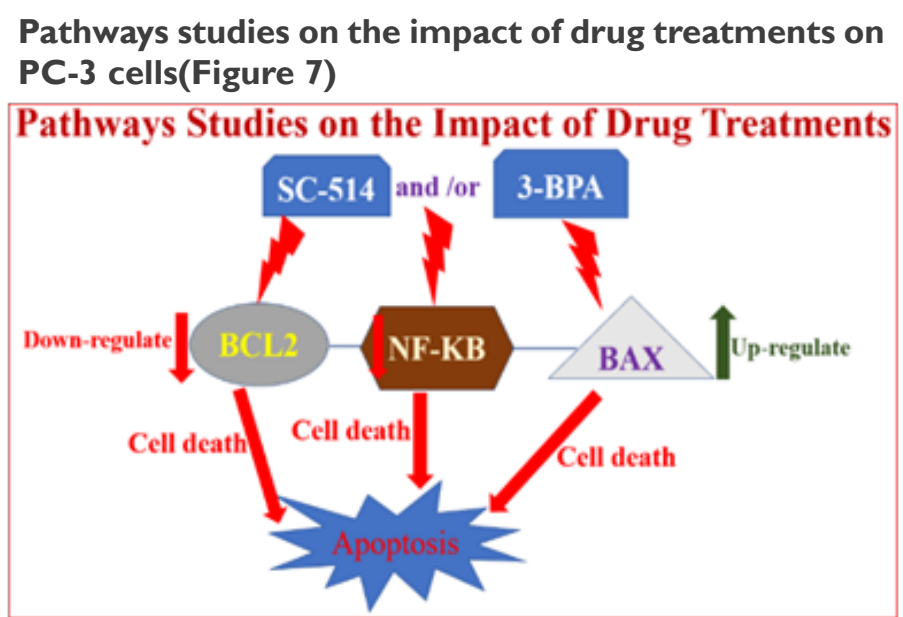

Figure 7 Indicates the impact of drug treatment on different pathways controlling prostate cancer carcinogenesis. This figure shows that SC-5I4 and/3-BPA treatments reduce NF-KB activation and BCL2 expression thereby promoting cell death via apoptosis ( NF-KB and BCL2 are apoptotic proteins because they are major survival pathways for prostate cancer). On the other hand, SC-5I4 and/3-BPA treatments upregulateBax expression leading to induction of apoptosis because Bax proteins are pro-apoptotic protein.

\section{Discussion}

High systemic concentrations of chemotherapeutic drugs is still a major problem causing toxicities to the body of prostate cancer patients after drug treatment. ${ }^{100}$ Current chemotherapeutic drugs are not capable of solving the problem of systemic toxicities because large doses of drugs are required to reduce proliferation of prostate cancer cells. ${ }^{101}$ Drug toxicity persist when there is drug resistance despite the large dose of drug administered in prostate cancer treatment. ${ }^{6,102,103}$ Hence, this study utilized new drug combinations (3-BPA and SC514) strategy to reduce MDR in prostate cancer treatment.

In our previous studies we showed that there was: a positive correlation between the concentration of SC-514 and/or 3-BPA and cell death; moderate correlation between ROS released and cell death. ${ }^{16}$ Our previous studies indicated that 3-BPA potentiate the therapeutic effect of SC-514 16 and other chemotherapeutic drugs. ${ }^{104}$ Previous studies proposed 3-BPA as a promising multidrug resistance reversal compound. ${ }^{105,106}$ Multidrug resistance reversal by 3-BPA occurred through at least three approaches. These approaches are; decrease in the intracellular level of ATP and HK-II bioactivity, the inhibition of ATPase activity, and the slight decrease in P-glycoprotein expression. ${ }^{105,107}$ Hence, in this study we utilized 3-BPA and SC-514 combination treatments to reduce MDR in prostate cancer treatment. SC-514 has been shown to reduce the expression of proteins that contribute to prostate cancer carcinogenesis such as NF-KB. ${ }^{103}$ $\mathrm{NF}-\kappa \mathrm{B}$-induced gene expression contributes significantly to the pathogenesis of inflammatory diseases such as cancer. ${ }^{108} \mathrm{SC}-514$ was previously indicated as inhibitor of NF-KB expression levels. ${ }^{108}$ However, the anticancer effect of SC-514 is limited because of poor solubility in polar solvents such as water. ${ }^{109}$ This study combines SC514 with 3-BPA to reduce MDR PC-3 cells because our previous research indicated a synergistic effect between 3-BPA and SC-514. ${ }^{103}$

Synergistic effect between 3-BPA and SC-514 formed the basis for utilizing the combination treatment of 3-BPA and SC-514 to reduce MDR in PC-3 prostate cancer cells. There was downregulation of multidrug resistant proteins and genes after treatment of $\mathrm{PC}-3$ prostate cancer cells with 3-BPA and/or SC-514.The double treatment with SC-514 and 3-BPA decreased multidrug resistance more efficiently when compared to single treatments of either 3-BPA and SC-514.

Overall, increase in concentration of drug appear to favor intracellular retention of drug in all treatments (Table $1 \& 2$ ). Hence, a reduction in the number of MDR 1 cells was observed in all treatment group as concentration of 3-BPA and/or SC-514 increases (Figure 4A $\& 4 \mathrm{~B})$.

Owing to the cellular heterogeneity of most tumors and the subsequent heterogeneity of P-170 expression (resistant cells may be present as clusters within a given tumor), this study utilized a an investigational technique, specificallyimmunohistochemistry, that can provide direct morphological confirmation of the presence of P- 170 rather than "bulk" methods such as western blotting and molecular biological techniques such as co-immunoprecipitation. ${ }^{78}$

Despite utilizing immunohistochemistry in this study, the effects of oxidative phosphorylation (OXPHOS) inhibition by 3-BPA and/ or SC-514 was not fully elucidated. 3-BPA and/or SC-514 treatment allowed a subpopulation of GR-PC-3 and PC-3 prostate cancer cells to live. Hence, the condition of multidrug resistance in prostate cancer persisted in some cells after treatment with 3-BPA and SC514 combination. Future studies will utilize PLGA polymer to deliver the combination treatment because PLGA will further increase the therapeutic efficiency of SC-514 by increasing its solubility and drug efficiency. ${ }^{109}$ Combination of SC-514 and 3-BPA was the most effective in depleting ATP energy in GR-PC-3 cells (Figure 3). This is in line with the result from the study that showed that genistein inhibits the activation of NF- $\mathrm{kB}$ and Akt signaling pathways, both of which are known to maintain a homeostatic balance between cell survival and apoptosis. ${ }^{110}$ SC-514 reduces p-glycoprotein expression in PC-3 prostate cancer cells. However, combination of SC-514 and 3 -BPA was the most effective in reducing p-glycoprotein expression in PC-3 prostate cancer cells (Figure 4A \& 4B).

A similar study showed that SC-514 inhibits transcription of NFkappa B-dependent genes in IL-1 beta-induced rheumatoid arthritisderived synovial fibroblasts in a dose-dependent manner. ${ }^{108}$ The effect of SC-514 on cytokine gene expression may be a combination of inhibiting I kappa B alpha phosphorylation/degradation, affecting NF-kappa B nuclear import/export as well as the phosphorylation and transactivation of p65. ${ }^{108} \mathrm{Hence}$, this study investigated the impact of SC-514 and/3-BPA on NF-KB activation and activation of other pathways like IL-6, BCL2 and Bax. Interleukin-6 is responsible for drug resistance and anti-apoptotic effects in prostatic cancer cells. ${ }^{111}$ NF-KB is a family of highly conserved transcription factors that regulate inflammatory response. ${ }^{112}$ SC-514 and/3-BPA treatments reduce NF-KB activation, IL-6 expression, and BCL2 (NF-KB, IL-6 and BCL2 are anti-apoptotic protein). However, SC-514 and/3-BPA treatments increase the expression of Bax because Bax is a proapoptotic protein. Apoptosis mode of cell death in PC-3 cells was increased by downregulation of IL-6, BCL2 and NF-KB. At the same time, apoptosis mode of cell death in PC-3 cells was elevated by upregulation of Bax protein.

\section{Conclusion}

The synergistic effect between 3-BPA and SC-514 was strong enough to reduce MDR in PC-3 and GR-PC-3 prostate cancer cell 
lines significantly. There was downregulation of multidrug resistant proteins and anti-apoptotic genes (NF-KB, IL-6, and BCL2) after treatment of GR-PC-3 and PC-3 prostate cancer cells with 3-BPA and/ or SC-514. Apoptotic death in prostate cancer treatment with 3-BPA and SC-514 was elevated by increased expression of pro-apoptotic proteins (Bax) and decreased expression of anti-apoptotic proteins (NF-KB, IL-6 and BCL2).

3-BPA may be a good potentiator of other chemotherapeutic drugs with similar mechanism of action as SC-514. Combination drug treatments of other chemotherapeutic drugs may be equally or more effective in reducing the incidence of drug resistance and drug toxicities in prostate cancer treatments.

\section{Materials and methods}

\section{Experiment I: MTT tetrazolium assay}

MTT Tetrazolium assay was performed to assess the cell viability of the prostate cancer cells after treatment with genistein. Results from this experiment will determine if a population of prostate cancer cells will survive after treatment with genistein. Briefly, PC-3prostate cancer cells were seeded at a density of 2500 cells /well in 96-well plate. These cells were incubated at $37^{\circ} \mathrm{C}$ and $5 \% \mathrm{CO}_{2}$ for $48 \mathrm{hrs}$ (until they reach their log phase and $80-90 \%$ of confluence). These cells were treated with genistein at their log phase for $48 \mathrm{hrs}$. $20 \mu \mathrm{l}$ of MTT $(5 \mu \mathrm{g} / \mathrm{ml})$ were added to the wells in the 96 well plate after the media was removed from the wells. The cells and MTT solution in the wells were incubated for $4 \mathrm{hrs}$ at $37^{\circ} \mathrm{C}$. The yellow tetrazolium MTT (3-(4, 5-dimethylthiazolyl-2)-2, 5-diphenyltetrazolium bromide) (Invitrogen) was reduced by metabolically active prostate cancer cells after treatment (treatment with genistein), by the action of dehydrogenase enzymes, to generate reducing equivalents such as NADH and NADPH. The resulting intracellular purple formazan was solubilized by adding $50 \mu 1 \mathrm{DMSO}$ to each well and quantified by spectrophotometric means using ELISA plate reader (Biotek ELx800). The absorbance was measured at $570 \mathrm{~nm}$. The absorbance values recorded was a measure of live cells in each well after drug treatment.

\section{Experiment 2: CellTiter-Glo®luminescent cell viability assay}

The CellTiter-Glo ${ }^{\circledR}$ Luminescent Cell Viability Assay is a homogeneous method utilized to determine the number of viable cells in GR-PC-3 prostate cancer cell culture based on quantitation of the ATP present, an indicator of metabolically active cells. This study used CellTiter-Glo ${ }^{\circledR}$ Assay in 96 well formats, for the purpose of assessing cell proliferation of GR-PC-3 prostate cancer cells after drug treatment.

Briefly, GR-PC-3 prostate cancer cells were seeded at a density of 2500 cells /well in 96-well plate. These cells were incubated at $37^{\circ} \mathrm{C}$ and $5 \% \mathrm{CO}_{2}$ for $48 \mathrm{hrs}$ (until they reach their log phase and 80 $90 \%$ of confluence). These cells were treated with 3-BPA and/or SC514 at their log phase for $48 \mathrm{hrs}$. The single reagent (CellTiter-Glo $\mathbb{}$ Reagent) (Cat. \# G7570 in the homogeneous state) was added directly to cells cultured in serum-supplemented medium. Cell washing, removal of medium and multiple pipetting steps is not required. The system detects as few cells/well in a 96-well format in 10 minutes after adding reagent and mixing.

The homogeneous "add-mix-measure" format results in cell lysis and generation of a luminescent signal proportional to the amount of ATP present in the treated PC-3 prostate cancer cells. The amount of ATP is directly proportional to the number of cells present in culture. The CellTiter-Glo $\AA$ Assay generates a "glow-type" luminescent signal, which has a half-life generally greater than five hours, depending on cell type and medium used. The extended half-life eliminates the need to use reagent injectors and provides flexibility for continuous or batch mode processing of multiple plates. This unique homogeneous format avoids errors that may be introduced by other ATP measurement methods that require multiple steps. Assay were performed as described in product protocol. Luminescence was recorded using citation imaging reader (BioTek) 10 minutes after reagent addition.

\section{Experiment 3:Immunofluorescence studies on treated prostate cancer cells}

Functionalization of chemotherapy drug with a fluorescent tag offers a useful visualization tool for tracing, localization, and clearance studies of chemotherapy drugs. This study was carried out by labeling 3-BPA and/or SC-514 drug with Cell Tracker ${ }^{\mathrm{TM}}$ Red CMPTX dyes (Life Technologies Catalog number: C34552) before treating the PC-3 and G-PC-3 prostate cancer cells. P-glycoprotein in drug resistant and sensitive viable $\mathrm{PC}-3$ cells were tested for reactivity with p-170 antibody by indirect immunofluorescence studies. During this immunofluorescence studies only cell the surface components of viable prostate cells are recognized. ${ }^{113}$

Briefly, PC-3 prostate cancer cells were cultured at 2500 cells $/ \mathrm{ml}$ in 96 well plates. These cells were treated with 3-BPA and/or SC514 for $48 \mathrm{hrs}$.After $48 \mathrm{hrs}$ PC-3 prostate cancer cells were adjusted to a concentration of $1 \times 10^{6}$ cells $/ \mathrm{ml}$ in PBS and $100 \mu 1$ of the cell suspension was aliquoted into each of two Eppendorf tubes. A volume of $100 \mu 1$ antibody ( 1 in 100 dilution of antibody in PBS) was added to one tube and $100 \mu 1$ of control irrelevant mouse ascites (diluted 1 in 100 in PBS) was added to the other. The tubes were mixed and incubated for 30 minutes at $4{ }^{\circ} \mathrm{C}$. The primary antibody was removed by centrifugation of cells at $1000 \mathrm{rpm}$ for five minutes. The cells were washed three times with PBS using the same procedure and $100 \mu 1$ of Goat anti-Mouse IgG, IgM (H+L) Secondary Antibody, FITC (Life Technologies Corporation, catalogue number A11059 Lot\# 1910746) diluted 1 in 50 in PBS was added. The tubes were mixed and incubated for 30 minutes at $4^{\circ} \mathrm{C}$ after which the secondary antibody was removed, and the cells were washed as mentioned previously. Each cell pellet was re-suspended in PBS and mounted on a slide for observation under confocal microscopy (Nikon A1R Confocal System w/SIM).

\section{Measuring the quantity of drug inside the cell under the confocal microscope}

Confocal microscopes are capable of magnifying objects up to 1,000 times and more. Objects as small as 100 nanometers can be seen in detail with these microscopes. In this study, we estimated the amount of drug inside the treated prostate cancer cells using a slide rule or a transparent metric ruler in conjunction with the different objective lenses. By measuring the field of view, we estimated the amount of 3-BPA and/or SC-514 inside treated G-PC-3 and PC-3 prostate cancer cells. Microscopes are not the same, therefore the fields of view are calibrated for the microscope utilized in order to record an accurate measurement. 
The microscope was switched on; the lowest-power objective lens (4x object) was selected. The slide scale or transparent metric ruler was placed on the stage and brought into focus in the eyepiece.The ruler was positioned so that the outer edge of one of the black hash marks is flush with the widest edge of the field of view. The number of lines and spaces it takes to cross the field of view to find its diameter was counted. For example, if four black lines and half the fourth space are visible, we can say the field of view is $4.5 \mathrm{~mm}$ in diameter.

The next highest objective lens was utilized, and the slide ruler was repositioned to measure the field of view. The same procedure was repeated for all the objective lenses. The slide containing the specimen was placed on the stage and the most appropriate objective lens was utilized for the final measurement and standard for this study. The objective lens that allows you to fill most of the field of view is the best for estimating size. The size of the specimen was estimated using the field-of-view measurements as a guide. For example, if there is about half a millimeter of empty space on either side of the $4 x$ lens, which we measured at $4.5 \mathrm{~mm}$, the specimen would be $3.5 \mathrm{~mm}$. In this study, we established a standard that specimen size (drug inside the cells) greater than $3 \mathrm{~mm}=$ abundant, specimen size (drug inside the cells) between $1 \mathrm{~mm}-3 \mathrm{~mm}=$ traces, specimen size (drug inside the cells) less than $1 \mathrm{~m}=$ less than traces.

\section{Experiment 4: ELISA assay}

In this study, ELISA (enzyme-linked immunosorbent assay) was utilized as a plate-based assay technique designed for detecting and quantifying proteins and antibodies. In this ELISA assay, the antigen of interest was immobilized to a solid surface and then complexed with the complementing antibody that is linked to an enzyme. Detection is accomplished by assessing the conjugated enzyme activity via incubation with a substrate to produce a measurable product. The most crucial element of the detection strategy is a highly specific antibody-antigen interaction.

These ELISAs were performed in 96-well polystyrene plates, which passively bonded antibodies and proteins. The binding and immobilization of reagents makes ELISAs simple to design and perform. Having the reactants of the ELISA immobilized to the microplate surface enables easy separation of bound from non-bound material during the assay. This ability to wash away non-specifically bound materials makes the ELISA a powerful tool for measuring specific analytes within a crude preparation.

Briefly, PC-3 prostate cancer cells were seeded at a density of 2500 cells /well in 96-well plate. These cells were incubated at $37^{\circ} \mathrm{C}$ and $5 \% \mathrm{CO}_{2}$ for $48 \mathrm{hrs}$ (until they reach their log phase and $80-90 \%$ of confluence). These cells were treated with 3-BPA and/SC-514 for $48 \mathrm{hrs}$. Sample lysate was prepared from the reagent, $50 \mu \mathrm{l}$ of sample from treated PC-3 cells or $50 \mu 1$ of lysis mix (negative control) or $50 \mu 1$ of control lysate (positive control) was added to InstantOne ELISA microplate wells. $50 \mu 1$ of freshly prepared antibody cocktail was added to each of the test wells. The InstantOne ELISA microplatewells was incubated for $1 \mathrm{hr}$ at room temperature while shaking at 300rp. The plate was washed three times using $200 \mu$ l PBS per well. The detection reagent was removed from $4^{\circ} \mathrm{C}$ and allowed to warm to room temperature. $100 \mu 1$ of detection reagent was added to each well and incubated for 30 minutes while shaking at 300rpm. $100 \mu 1$ stop solution was added to each well and the absorbance at $450 \mathrm{~nm}$ was read using colorimetric plate reader (Biotek ELx800).

\section{NF-KB activation measurement using ELISA}

NF-KB P65 TOTAL/PHOS ELISA (catalog number 85-86083-11) was used for this experiment. The InstantOne ${ }^{\mathrm{TM}}$ ELISA is specifically engineered for accurate measurement of total and phosphorylated human NFkB p65 in cell lysates. The InstantOne ${ }^{\mathrm{TM}}$ ELISA kit allows for fast analysis of samples in approximately one hour. All reagents used in a traditional sandwich ELISA are added in solution to a plate followed by a wash step and detection with the TMB colorimetric substrate.

\section{Human IL-6 expression measurement using ELISA (Mini TMB ELISA Development Kit)}

Human IL-6 ELISA development kit contains the key components required for the quantitative measurement of natural and/or recombinant human IL-6 in a sandwich ELISA format. The ELISA protocol, the recommended microplates, reagents and solutions, the components supplied in the kit were enough to assay human IL-6 in approximately 200 ELISA plate wells as described in the protocol above. This ELISA Kit (Peprotech) includes: Capture Antibody, Detection Antibody, Protein Standard, HRP-Conjugate

\section{$B C L$ activation measurement using ELISA}

HUMAN BCL2L2 (BCL-W) ELISA96 ASSAYS (EHBCL2L2 Lot\# 57082718) was used as described above.

\section{BAX activation measurement using ELISA}

ANTI-HU BAX100UG (BMS162 Lot\# 191244000) was used as described above.

\section{Acknowledgments}

None.

\section{Conflicts of interest}

The authors declare there are no conflicts of interest.

\section{Funding}

None.

\section{References}

1. Finianos A, Aragon-Ching JB. Zoledronic acid for the treatment of prostate cancer. Expert Opin Pharmacother. 2019;20(6):657-666.

2. American Cancer Society, Key statistics for prostate Cancer. Prostate cancer facts. 2018.

3. Powell IJ. Epidemiology and Pathophysiology of Prostate Cancer in African-American Men. J Urol. 2007;177(2):444-449.

4. Hsing AW, Yeboah E, Biritwum R, et al. High prevalence of screen detected prostate cancer in West Africans: Implications for racial disparity of prostate cancer. J Urol. 2014;192(3):730-735.

5. Huggins C. The Hormone-Dependent Cancers. Bull N Y Acad Med. 1963;39(11):752-757.

6. Semenas J, Allegrucci C, Boorjian SA, et al. Overcoming drug resistance and treating advanced prostate cancer. Curr Drug Targets. 2012;13(10):1308-1323.

7. Carroll PR, Parsons JK, Andriole G, et al. Prostate Cancer Early Detection, Version 2.2015. J Natl Compr Canc Netw. 2015;13:15341561 . 
8. Loblaw DA, Virgo KS, Nam R, et al. Initial hormonal management of androgen-sensitive metastatic, recurrent, or progressive prostate cancer: 2006 update of an American Society of Clinical Oncology practice guideline. J Clin Oncol. 2007;25(12):1596-1605.

9. Beth A Hellerstedt, Kenneth J Pienta. The current state of hormonal therapy for prostate cancer. CA Cancer J Clin. 2002;52(3):154-179.

10. Michelle Ojemuyiwa, Karen Zeman, Alexander Spira. Complete Metabolic Response of Metastatic Castration-resistant Neuroendocrine Carcinoma of the Prostate After Treatment with RRx-001 and Reintroduced Platinum Doublets. Eur Urol. 2018;6(12):2478-2481.

11. El Sayed SM. Enhancing anticancer effects, decreasing risks and solving practical problems facing 3-bromopyruvate in clinical oncology: 10 years of research experience. Int $J$ Nanomedicine. 2018;13:4699-4709.

12. Toledano MB, Leonard WJ. Modulation of transcription factor NF-kB binding activity by oxidation-reduction in vitro. Proc Natl Acad Sci USA. 1991;88(10):4328-4332.

13. Jin $\mathrm{R}$, Yi Y, Yull FE, et al. Nf-kb gene signature predicts prostate cancer progression. Cancer Res. 2014;74(10):2763-2772.

14. Toledano MB, Ghosh D, Trinh F, et al. N-Terminal DNA-Binding Domains Contribute to Differential DNA-Binding Specificities of NF-KB p50 and p65. Mol Cell Biol. 1993;13(2):852-860.

15. Kai-Wing Tse A, Chen YJ, et al. Sensitization of melanoma cells to alkylating agent-induced DNA damage and cell death via orchestrating oxidative stress and IKK $\beta$ inhibition. Redox Biol. 2017;11:562-576.

16. Oloruntobi Famuyiwa T, Jebelli J, Kumi Diaka JK, et al. Interaction between 3-Bromopyruvate and SC-514 in prostate cancer treatment. $J$ Cancer Prev Curr Res. 2018;9(6):270-280.

17. Chen J, Cao S, Situ B, et al. Metabolic reprogramming-based characterization of circulating tumor cells in prostate cancer. $J$ Exp Clin Cancer Res. 2018;37(1):127.

18. Ippolito L, Marini A, Cavallini L, et al. Metabolic shift toward oxidative phosphorylation in docetaxel resistant prostate cancer cells. Oncotarget. 2016;7(38):61890-61904.

19. Lake DE, Hudis CA. High-dose chemotherapy in breast cancer Drugs. 2004;64(17):1851-1860.

20. Zhu H, Chen H, Zeng X, et al. Co-delivery of chemotherapeutic drugs with vitamin E TPGS by porous PLGA nanoparticles for enhanced chemotherapy against multi-drug resistance. Biomaterials. 2014;35(7):2391-2400.

21. Dorai T, Aggarwal BB. Role of chemopreventive agents in cancer therapy. Cancer Lett. 2004;215(2):129-140.

22. Joyce H, McCann A, Clynes M, et al. Influence of multidrug resistance and drug transport proteins on chemotherapy drug metabolism. Expert Opin Drug Metab Toxicol. 2015;11(5):795-809.

23. Zhang YK, Wang YJ, Gupta P, et al. Multidrug Resistance Proteins (MRPs) and Cancer Therapy. AAPS J. 2015;17(4):802-812.

24. Choi $\mathrm{CH}$. $\mathrm{ABC}$ transporters as multidrug resistance mechanisms and the development of chemosensitizers for their reversal. Cancer Cell Int. 2005;5:30.

25. Kathawala RJ, Gupta P, Ashby CR, et al. The modulation of ABC transporter-mediated multidrug resistance in cancer: A review of the past decade. Drug Resist Updat. 2015;18:1-17.

26. Correia AL, Bissell MJ. The tumor microenvironment is a dominant force in multidrug resistance. Drug Resist Updat. 2012;15(1-2):3949
27. Meng X, Liao S, Wang X, et al. Reversing P-glycoprotein-mediated multidrug resistance in vitro by $\alpha$-asarone and $\beta$-asarone, bioactive cis-trans isomers from Acorus tatarinowii. Biotechnol Lett. 2014;36(4):685-691.

28. Piecuch A, Obłąk E. Yeast ABC proteins involved in multidrug resistance. Cell Mol Biol Lett. 2014;19(1):1-22.

29. Hulleman E, Kazemier KM, Holleman A, et al. Inhibition of glycolysis modulates prednisolone resistance in acute lymphoblastic leukemia cells. Blood. 2009;113(9):2014-2021.

30. Wu AML, Dalvi P, Lu X, et al. Induction of multidrug resistance transporter ABCG2 by prolactin in human breast cancer cells. Mol Pharmacol. 2013;83(2):377-388.

31. Zahreddine H, Borden KLB. Mechanisms and insights into drug resistance in cancer. Front Pharmacol. 2013;4:28.

32. Ling V. Multidrug resistance: molecular mechanisms and clinical relevance. Cancer Chemother Pharmacol. 1997;40:S3-S8.

33. Ni LN, Li JY, Miao KR, et al. Multidrug resistance gene (MDR1) polymorphisms correlate with imatinib response in chronic myeloid leukemia. Med Oncol. 2011;28(1):265-269.

34. Choudhuri S, Klaassen CD. Structure, Function, Expression, Genomic Organization, and Single Nucleotide Polymorphisms of Human ABCB1 (MDR1), ABCC (MRP), and ABCG2 (BCRP) Efflux Transporters. Int J Toxicol. 2006;25(4):231-259.

35. Callaghan R, Luk F, Bebawy M. Inhibition of the multidrug resistance P-glycoprotein: Time for a change of strategy? Drug Metab Dispos. 2014;42(4):623-631.

36. Seebacher NA, Richardson DR, Jansson PJ. A mechanism for overcoming P-glycoprotein-mediated drug resistance: Nove combination therapy that releases stored doxorubicin from lysosomes via lysosomal permeabilization using Dp44mT or DpC. Cell Death Dis. 2016;7(12):e2510.

37. Yamato I, Sho M, Shimada K, et al. PCA-1/ALKBH3 contributes to pancreatic cancer by supporting apoptotic resistance and angiogenesis. Cancer Res. 2012;72(18):4829-4839.

38. Lara PN, Ely B, Quinn DI, et al. Serum biomarkers of bone metabolism in castration-resistant prostate cancer patients with skeletal metastases: Results from SWOG 0421. J Natl Cancer Inst. 2014;106(4):dju013.

39. Higano C, Shields A, Wood N, et al. Bone mineral density in patients with prostate cancer without bone metastases treated with intermittent androgen suppression. Urology. 2004;64(6):1182-1186.

40. Coleman RE. Clinical features of metastatic bone disease and risk of skeletal morbidity. Clin Cancer Res. 2006;12(20 Pt 2):6243-6250.

41. Singh VA, Haseeb A, Alkubaisi AAHA. Incidence and outcome of bone metastatic disease at University Malaya Medical Centre. Singapore Med J. 2014;55:539-546.

42. Zheng J. Energy metabolism of cancer: Glycolysis versus oxidative phosphorylation (review). Oncol Lett. 2012;4(6):1151-1157.

43. Burger C, Wick M, Brusselbach S, et al. Differential induction of "metabolic genes" after mitogen stimulation and during normal cell cycle progression. J Cell Sci. 1994;107(Pt 1):241-252.

44. Legaspi A, Jeevanandam M, Starnes HF, et al. Whole body lipid and energy metabolism in the cancer patient. Metabolism 1987;36(10):958-963.

45. Hyltander A, Drott C, Körner U, et al. Elevated energy expenditure in cancer patients with solid tumours. Eur J Cancer Clin Oncol. 1991;27(1):9-15. 
46. Baron A, Migita T, Tang D, et al. Fatty acid synthase: A metabolic oncogene in prostate cancer? J Cell Biochem. 2004;91(1):47-53.

47. Epstein JI, Carmichael M, Partin AW. OA-519 (fatty acid synthase) as an independent predictor of pathologic state in adenocarcinoma of the prostate. Urology. 1995;45(1):81-86.

48. Rossi S, Graner E, Febbo P, et al. Fatty acid synthase expression defines distinct molecular signatures in prostate cancer. Mol Cancer Res. 2003;1:707-715.

49. Pizer ES, Chrest FJ, DiGiuseppe JA, et al. Pharmacological inhibitors of mammalian fatty acid synthase suppress DNA replication and induce apoptosis in tumor cell lines. Cancer Res. 1998;58(20):46114615 .

50. Li JN, Gorospe M, Chrest FJ, et al. Pharmacological inhibition of fatty acid synthase activity produces both cytostatic and cytotoxic effects modulated by p53. Cancer Res. 2001;61(4):1493-1499.

51. De Schrijver E, Brusselmans K, Heyns W, et al. RNA interferencemediated silencing of the fatty acid synthase gene attenuates growth and induces morphological changes and apoptosis of LNCaP prostate cancer cells. Cancer Res. 2003;63(13):3799-3804.

52. Miccheli A, Tomassini A, Puccetti C, et al. Metabolic profiling by 13C-NMR spectroscopy: [1,2-13C2]glucose reveals a heterogeneous metabolism in human leukemia T cells. Biochimie. 2006;88(5):437448.

53. Berridge MV, Herst PM, Tan AS. Metabolic flexibility and cell hierarchy in metastatic cancer. Mitochondrion. 2010;10(6):584-588.

54. Chen JL, Lucas JE, Schroeder T, et al. The genomic analysis of lactic acidosis and acidosis response in human cancers. PLoS Genet. 2008;4(12):e1000293.

55. Marusyk A, Polyak K. Tumor heterogeneity: Causes and consequences. Biochim Biophys Acta Rev Cancer. 2010;1805(1):105-117.

56. Zhang Z, Su T, He L, et al. Identification and Functional Analysis of Ligands for Natural Killer Cell Activating Receptors in Colon Carcinoma. Tohoku J Exp Med. 2010;226(1):59-68.

57. Chang L, Graham PH, Hao J, et al. Emerging roles of radioresistance in prostate cancer metastasis and radiation therapy. Cancer Metastasis Rev. 2014;33(2-3):469-496.

58. Darwish OM, Raj GV. Management of biochemical recurrence after primary localized therapy for prostate cancer. Front Oncol. 2012;2:48

59. Li P, Yang R, Gao WQ. Contributions of epithelial-mesenchymal transition and cancer stem cells to the development of castration resistance of prostate cancer. Mol Cancer. 2014;13:55.

60. Rybak AP, Bristow RG, Kapoor A. Prostate cancer stem cells: Deciphering the origins and pathways involved in prostate tumorigenesis and aggression. Oncotarget. 2015;6(4):1900-1919.

61. Sharpe B, Beresford M, Bowen R, et al. Searching for Prostate Cancer Stem Cells: Markers and Methods. Stem Cell Rev Reports. 2013;9(5):721-730

62. Deng Q, Tang DG. Androgen Receptor and Prostate Cancer Stem Cells : Biological Mechanisms and Clinical Implications. Endocr Relat Cancer. 2015;22(6):T209-T220.

63. Gottesman MM, Fojo T, Bates SE. Multidrug resistance in cancer: role of ATP-dependent transporters. Nat Rev Cancer. 2002;2(1):4858 .

64. Moran E, Larkin A, Doherty G, et al. A new mdr-1 encoded P-170 specific monoclonal antibody: $(6 / 1 \mathrm{C})$ on paraffin wax embedded tissue without pretreatment of sections. J Clin Pathol. 1997;50(6):465-471.
65. Cole S, Bhardwaj G, Gerlach J, et al. Overexpression of a transporter gene in a multidrug-resistant human lung cancer cell line. Science. 1992;258(5088):1650-1654.

66. Zaman GJ, Flens MJ, van Leusden MR, et al. The human multidrug resistance-associated protein MRP is a plasma membrane drug-efflux pump. Proc Natl Acad Sci USA. 1994;91(19):8822-8826.

67. Hofmann G, Mattern MR. Topoisomerase II in multiple drug resistance. Cytotechnology. 1993;12(1-3):137-154.

68. Moscow JA, Dixon KH. Glutathione-related enzymes, glutathione and multidrug resistance. Cytotechnology. 1993;12(1-3):155-170.

69. Clynes M. Cellular models for multiple drug resistance in cancer. Anim J Soc Vitr Biol. 1993;29:169-188.

70. Kumar RM, Collins JJ. Cellular signal processing: Out of one, many. Mol Cell. 2012;45(3):143-144.

71. Kaye SB. P glycoprotein (P-gp) and drug resistance time for reappraisal? Br J Cancer. 1993;67(4):641-643.

72. Lee CT, Capodieci P, Osman I, et al. Overexpression of the cyclindependent kinase inhibitor p16 is associated with tumor recurrence in human prostate cancer. Clin Cancer Res. 1999;5(5):977-983.

73. Kartner N, Evernden-Porelle D, Bradley G, et al. Detection of P-glycoprotein in multidrug-resistant cell lines by monoclonal antibodies. Nature. 1985;316(6031):820-823.

74. Scheper RJ, Bulte JWM, Brakkee JGP, et al. Monoclonal antibody JSB-1 detects a highly conserved epitope on the P-glycoprotein associated with multi-drug-resistance. Int J Cancer. 1988;42(3):389394.

75. Hamada H, Tsuruo T. Functional role for the 170 - to $180-\mathrm{kDa}$ glycoprotein specific to drug- resistant tumor cells as revealed by monoclonal antibodies. Proc Natl Acad Sci USA. 1986;83(20):77857789 .

76. Chu TM, Kawinski E, Lin TH. Characterization of a new monoclonal antibody F4 detecting cell surface epitope and P-glycoprotein in drugresistant human tumor cell lines. Hybridoma. 1993;12(4):417-429.

77. Schneider J, Romero H. Correlation of P-glycoprotein overexpression and cellular prognostic factors in formalin fixed, paraffin-embedded tumor samples from breast cancer patients. Anticancer Res. 1995;15(3):1117-1121.

78. Wishart GC, Plumb JA, Going JJ, et al. P-glycoprotein expression in primary breast cancer detected by immunocytochemistry with two monoclonal antibodies. Br J Cancer. 1990;62:758-761.

79. Thiebaut F, Currier SJ, Whitaker J, et al. Activity of the multidrug transporter results in alkalinization of the cytosol: measurement of cytosolic $\mathrm{pH}$ by microinjection of a $\mathrm{pH}$-sensitive dye. $J$ Histochem Cytochem. 1990;38(5):685-690.

80. Beck WT, Grogan TM, Willman CL, et al. Methods to detect P-glycoprotein-associated multidrug resistance in patients' tumors: Consensus recommendations. Cancer Res. 1996;56(13):3010-3020.

81. Callen DF, Baker E, Simmers RN, et al. Localization of the human multiple drug resistance gene, MDR1, to 7q21.1. Hum Genet. 1987;77(2):142-144.

82. Ambudkar SV, Kimchi-Sarfaty C, Sauna ZE, et al. P-glycoprotein: From genomics to mechanism. Oncogene. 2003:22(47):7468-7485.

83. Kitada K, Yamasaki T, Aikawa S. Amplification of the ABCB1 region accompanied by a short sequence of $200 \mathrm{bp}$ from chromosome 2 in lung cancer cells. Cancer Genet Cytogenet. 2009;194(1):4-11. 
84. Wu L, Birle DC, Tannock IF. Effects of the mammalian target of rapamycin inhibitor CCI-779 used alone or with chemotherapy on human prostate cancer cells and xenografts. Cancer Res. 2005;65(7):2825-2831

85. Boldt $\mathrm{S}$, Weidle UH, Kolch W. The role of MAPK pathways in the action of chemotherapeutic drugs. Carcinogenesis. 2002;23(11):18311838 .

86. Zelivianski S, Spellman M, Kellerman M, etal.ERK inhibitor PD98059 enhances docetaxel-induced apoptosis of androgen-independent human prostate cancer cells. Int J Cancer. 2003;107(3):478-485.

87. Boddy JL, Fox SB, Han C, et al. The androgen receptor is significantly associated with vascular endothelial growth factor and hypoxia sensing via hypoxia-inducible factors HIF-1a, HIF-2a, and the prolyl hydroxylases in human prostate cancer. Clin Cancer Res. 2005;11(21):7658-7663.

88. Rinaldo F, Li J, Wang E, et al. A regulates vascular endothelial growth factor-C (VEGF-C) synthesis in prostate cancer cells during androgen ablation. Oncogene. 2007;26(12):1731-1738.

89. Pollak M, Beamer W, Zhang JC. Insulin-like growth factors and prostate cancer. Cancer Metastasis Rev. 1998;17(4):383-390.

90. Nickerson T, Chang F, Lorimer D, et al. In vivo progression of LAPC9 and $\mathrm{LNCaP}$ prostate cancer models to androgen independence is associated with increased expression of insulin-like growth factor I (IGF-I) and IGF-I receptor (IGF-IR). Cancer Res. 2001;61(16):62766280 .

91. Zhu B, Kyprianou N. Transforming growth factor beta and prostate cancer. Cancer Treat Res. 2005;126:157-173.

92. Domingo-Domenech J, Oliva C, Rovira A, et al. Interleukin 6, a nuclear factor- $\kappa \mathrm{B}$ target, predicts resistance to docetaxel in hormoneindependent prostate cancer and nuclear factor- $\kappa \mathrm{B}$ inhibition by PS-1145 enhances docetaxel antitumor activity. Clin Cancer Res. 2006;12(18):5578-5586.

93. Mimeault M, Johansson SL, Vankatraman G, et al. Combined targeting of epidermal growth factor receptor and hedgehog signaling by gefitinib and cyclopamine cooperatively improves the cytotoxic effects of docetaxel on metastatic prostate cancer cells. Mol Cancer Ther. 2007;6(3):967-978.

94. Banerjee $\mathrm{S}$, Hussain $\mathrm{M}$, Wang $\mathrm{Z}$, et al. In vitro and in vivo molecular evidence for better therapeutic efficacy of ABT-627 and taxotere combination in prostate cancer. Cancer Res. 2007;67(8):3818-3826.

95. Lo Nigro C, Maffi M, Fischel JL, et al. The combination of docetaxel and the somatostatin analogue lanreotide on androgen-independent docetaxel-resistant prostate cancer: Experimental data. BJU Int. 2008;102(5):622-627.

96. Spagnuolo C, Russo GL, Orhan IE, et al. Genistein and Cancer: Current Status, Challenges, and Future Directions. Adv Nutr. 2015;6(4):108-419.

97. Kumi-Diaka J, Oseni SO, Famuyiwa T, et al. Therapeutic Impact of Vitamin $\mathrm{C}$ on the Anticancer Activities of Genistein Isoflavone in Radiosensitized Lncap Prostate Cancer Cells. J Cancer Prev Curr Res. 2015;2(4):00048.
98. Famuyiwa TO, Boe A, Diaka JK, et al. Enhancement of GenisteinInduced Apoptosis in LNCaP Prostate Cancer cells. J Cancer Prev Curr Res. 4(2):00111.

99. Zhang L, Li L, Wu D, et al. A novel anti-cancer effect of genistein: reversal of epithelial mesenchymal transition in prostate cancer cells. Acta Pharmacol Sin. 2008;29(9):1060-1068.

100. Lauschke VM, Ingelman-Sundberg M. The importance of patientspecific factors for hepatic drug response and toxicity. Int $J \mathrm{Mol} \mathrm{Sci}$. 2016;17(10):1714.

101. Alexander JL, Wilson ID, Teare J, et al. Gut microbiota modulation of chemotherapy efficacy and toxicity. Nat Rev Gastroenterol Hepatol. 2017;14(6):356-365.

102. Lippert TH, Ruoff HJ, Volm M. Current status of methods to assess cancer drug resistance. Int J Med Sci. 2011;8(3):245-253.

103. Terada N, Kamoto T, Tsukino H, et al. The efficacy and toxicity of cabazitaxel for treatment of docetaxel-resistant prostate cancer correlating with the initial doses in Japanese patients. BMC Cancer. 2019;19(1):156.

104. Ihrlund LS, Hernlund E, Khan O, et al. 3-Bromopyruvate as inhibitor of tumour cell energy metabolism and chemopotentiator of platinum drugs. Mol Oncol. 2008;2(1):94-101.

105. Wu L, Xu J, Yuan W, et al. The reversal effects of 3-bromopyruvate on multidrug resistance In Vitro and In Vivo derived from human breast MCF-7/ADR Cells. PLoS One. 2014;9(11):e112132.

106. Liu Z, Sun Y, Hong H, et al. 3-bromopyruvate enhanced daunorubicininduced cytotoxicity involved in monocarboxylate transporter 1 in breast cancer cells. Am J Cancer Res. 2015;5(9):2673-2685.

107. Thomas H, Coley HM. Overcoming multidrug resistance in cancer: An update on the clinical strategy of inhibiting P-glycoprotein. Cancer Control. 2003;10(2):159-165.

108. Kishore N, Sommers C, Mathialagan S, et al. A selective IKK-2 inhibitor blocks NF- $\kappa \mathrm{B}$-dependent gene expression in interleukin-1 $\beta$ stimulated synovial fibroblasts. J Biol Chem. 2003;278(35):3286132871.

109. Famuyiwa TO. A new approach for preparing SC-514 loaded plga particles by single emulsion method. J Med Pharm Allied Sci. 2019;2367-2380.

110. Banerjee S, Li Y, Wang Z, et al. Multi-targeted therapy of cancer by genistein. Cancer Lett. 2008;269(2):226-242.

111. Pu YS, Hour TC, Chuang SE, et al. Interleukin-6 is responsible for drug resistance and anti-apoptotic effects in prostatic cancer cells. Prostate. 2004;60(2):120-129.

112. Oeckinghaus A, Ghosh S. The NF-kappaB family of transcription factors and its regulation. Cold Spring Harb Perspect Biol. 2009;1(4):a000034.

113. Schachner M, Wortham KA, Ryberg MZ, et al. Brain cell surface antigens detected by anticorpus callosum antiserum. Brain Res. 1977;127(1):87-97. 